\title{
REPENSAR LA RELACIÓN ENTRE MIGRACIÓN Y DESARROLLO A PARTIR DEL CASO DE MÉXICO
}

\author{
Raúl Delgado Wise \\ Humberto Márquez Covarrubias
}

\begin{abstract}
Resumen: Este artículo examina la teoría y la práctica de la relación entre desarrollo y migración en el contexto de la integración económica de México a Estados Unidos. Ante los vacíos teórico-conceptuales del campo de estudio en la materia, se postula la necesidad de emprender un viraje epistémico para, a partir de la perspectiva de la economía política del desarrollo, concederle primacía explicativa a la problemática del desarrollo ante el fenómeno migratorio. Con miras a caracterizar los procesos esenciales del caso mexicano, se emplean dos categorías, exportación de fuerza de trabajo y desarrollo basado en las remesas, a fin de profundizar en las causas estructurales y en las prácticas estratégicas que configuran la naturaleza compleja del fenómeno.
\end{abstract}

Palabras clave: economía política del desarrollo, exportación de fuerza de trabajo, desarrollo basado en las remesas, México, Estados Unidos.

Enviado a dictamen: 12 de febrero de 2007.

Aprobación: 18 de septiembre de 2007.

Raúl Delgado Wise, doctor en Ciencias Sociales por la Universidad de Pensilvania, Director de la Unidad Académica en Estudios del Desarrollo de la Universidad Autónoma de Zacatecas y Director ejecutivo de la Red Internacional de Migración y Desarrollo, Temas de especialización: Migración y desarrollo, Economía política del desarrollo, correo electrónico: rdwise@estudiosdeldesarrollo.net. Humberto Márquez Covarrubias, doctor en Estudios del Desarrollo por la Universidad Autónoma de Zacatecas, Profesor-investigador del Doctorado en Estudios del Desarrollo de la Universidad Autónoma de Zacatecas, Temas de especialización: Migración y desarrollo, Economía política del desarrollo, correo electrónico: hmarquez@estudiosdeldesarrollo.net.
Abstract: This article examines the theory and the practice of the relation between development and migration in the context of the economic integration from Mexico to the United States. Before the theoretical-conceptual emptinesses of the field of study in the matter, thenecessity is postulated to undertake a epistémico turn for, from the perspective of the political economy of the development, to grant to him primacía explanatory to the problematic one of the development before the migratory phenomenon. With a view to characterizing the essential processes of the Mexicancase, two categories, export of work force and development based on the remittances are used, in order to deepen in the structural causes and the strategic practices that they form the complex nature of the phenomenon.

Key words: political economy of the development, export of work force, development based on the remittances, Mexico, the United States.

\section{Introducción}

$\mathrm{B}$ ajo el señuelo del "rostro humano de la globalización", un supuesto vínculo positivo entre la migración internacional y el desarrollo de los países de origen ha sido subrayado, con distintos énfasis, por los organismos internacionales encabezados por el Banco Mundial (BM) y el Banco Interamericano de Desarrollo (BID). Este planteamiento radica en la idea de que el flujo creciente de dinero enviado por 
los migrantes internacionales puede transmutarse en instrumento, palanca o motor del desarrollo de aquellos países y lugares donde se origina el caudaloso éxodo laboral hacia los países desarrollados del norte. Empero, no se propone ningún cambio en los ejes articuladores de la llamada globalización ni en la política neoliberal impuesta a rajatabla en los inermes países exportadores de migrantes; ambos vectores están en la base de la profundización del subdesarrollo y de la proliferación de la migración internacional. A lo sumo, se plantean estrategias llamadas de migración y desarrollo que, a decir verdad, apenas si tocan la superficie del fenómeno migratorio, con muy limitados alcances en términos de desarrollo. En esa tónica se inscribe la política de reducción de costos de transferencia de las remesas o la promoción de algunos instrumentos financieros para la inversión de remesas en microproyectos. En la misma sintonía, los gobiernos de los principales países especializados en la exportación de migrantes, México al frente, están adscritos a una supuesta política de migración y desarrollo instrumentada mediante un puñado de programas aislados y descontextualizados -incluso sin racionalidad institucional - frente a la complejidad de la problemática del desarrollo, y ajenos a la necesidad de generar un proyecto de desarrollo nacional en un nuevo esquema de integración económica regional capaz de reducir las asimetrías socioeconómicas entre países y contener - $\mathrm{o}$ al menos aminorar - la desbordante dinámica migratoria que prevalece en la actualidad.

El artículo tiene el cometido de dar cuenta de la complejidad teórica y práctica que representa la relación entre migración internacional y desarrollo en el capitalismo contemporáneo desde de la economía política del desarrollo, interdisciplinaria por definición. Esta perspectiva postula la necesidad de explicar la dinámica migratoria a partir de los problemas del desarrollo que se registran en los países subdesarrollados derivados de su inserción en la economía internacional. Por lo mismo, reconoce que los estudios circunscritos en la órbita de la migración y el desarrollo son de tal suerte restringidos porque presentan debilidades teórico-conceptuales, al grado que los constriñe a mostrar evidencias empíricas parciales e inconexas, muchas veces descontextualizadas. Es el caso señalado de aquellos planteamientos que quieren deducir el desarrollo, en cualquiera de sus modalidades, a partir de la expansión de la migración internacional y de la canalización del flujo de remesas a los lugares de origen.

Para dilucidar el caso de México, a la sazón primer exportador de migrantes y receptor de remesas en el mundo, amén de primer proveedor de fuerza de trabajo barata a la economía más grande del orbe, la estadounidense, nuestra perspectiva se vale de un par de categorías analíticas que explican un par de procesos concatenados dentro de la verdadera relación entre desarrollo y migración: i) modelo exportador de fuerza de trabajo barata, centrada en el papel de la fuerza de trabajo mexicana dentro del proceso de reestructuración productiva de la economía estadounidense, mediante la articulación de tres mecanismos: maquila, maquila encubierta y migración laboral. En esa lógica, la sociedad mexicana se configura como una sobrepoblación relativa dispuesta a incursionar en el mercado laboral transnacional bajo condiciones de elevada precarización laboral y exclusión social, y ii) modelo de desarrollo basado en las remesas, que explica cómo las remesas en lugar de constituirse en un instrumento del desarrollo - en consonancia al ideario del Posconsenso de Washington, cuya pretensión es imprimirle un rostro humano a la globalización neoliberal - profundizan una nueva forma de dependencia para cubrir la subsistencia social, merced a su naturaleza salarial, de vastos contingentes poblacionales y para apuntalar la precaria estabilidad macroeconómica del país.

El trabajo se divide en cuatro secciones. En la primera se revisan someramente los aportes, vacíos teóricos y limitaciones analíticas de los estudios de migración y desarrollo, al tiempo en que se plantea la necesidad de reconvertir el enfoque analítico para anteponer la problemática del desarrollo a la migración desde la 
perspectiva de la economía política del desarrollo. En la segunda se caracteriza la relación entre desarrollo y migración para el caso mexicano mediante el modelo exportador de fuerza de trabajo. En la tercera se devela la estrategia de desarrollo basado en las remesas como un proceso de dependencia que asigna a los migrantes la responsabilidad de promover el desarrollo en descargo de la obligación estatal correspondiente. Finalmente, a manera de conclusiones, se identifican las contradicciones de ambos modelos en tanto singo de su insustentabilidad.

\section{El abordaje de la relación entre migración y desarrollo}

La relación entre migración y desarrollo ha sido poco abordada en términos teóricos, según se puede constatar cuando se sigue la trayectoria no sólo de las teorías de la migración y las teorías del desarrollo, sino incluso de los estudios que acometen directamente la susodicha relación. Por lo que hace a las teorías dominantes de la migración internacional, particularmente las posestructurales y neoclásicas, se evidencia la descontextualización de sus explicaciones. En las condiciones actuales, son insuficientes para explicar ya no sólo el fenómeno migratorio en sí mismo sino también su relación con los problemas del desarrollo de los países emisores. El grueso de los estudios sobre migración internacional responde a la perspectiva e intereses latentes de los países receptores de inmigrantes y particularmente sus gobiernos y clases dominantes, de ahí que proliferen análisis sobre asimilación/integración, seguridad, diferenciales salariales, entre otras temáticas. En todos los casos se invisibiliza la relación positiva que existe entre la migración y el desarrollo en las sociedades receptoras, esto es, se esconde la contribución que los migrantes y sus países de origen hacen al desarrollo del país de destino. En tanto que en los países exportadores de emigrantes, en las pocas ocasiones en que los estudios migratorios atienten la problemática del desarrollo, ésta es abordada en un sentido restringido: se restringe a las posibles contribuciones que los migrantes puedan hacer al desarrollo, particularmente en el ámbito local. Más aún, las perspectivas teóricas que predominan en el campo de los estudios del desarrollo no consideran el problema de la migración, a no ser que se invoque como un factor secundario o una especie de externalidad.

El espectro teórico sobre el desarrollo es vasto y parte de paradigmas contrastantes que van desde las teorías de la modernización, estructuralistas, neoestructuralistas, dependentistas, sistema-mundo, sustentabilidad, neoliberalismo (que es la antítesis del desarrollo), regulacionismo, hasta la gama de enfoques que se engloba bajo el mote de desarrollo alternativo (participativo, centrado en la comunidad, etcétera) y el posdesarrollo. En la trayectoria histórica de la teoría y la práctica del desarrollo, después de la segunda guerra mundial, se advierte una visión acorde con los intereses de los países hegemónicos, principalmente Estados Unidos. En la década de los cincuenta predomina la perspectiva de la modernización como respaldo al proyecto imperialista en el contexto de guerra fría. No obstante, en América Latina se gesta, desde los sesenta, una visión donde la relación asimétrica entre desarrollo y subdesarrollo se coloca en el centro (estructuralismo de la CEPAL y teorías de la dependencia). Sin embargo, con la imposición del neoliberalismo, a fines de los setentas la preocupación por el desarrollo pasa a un segundo plano y se obstaculiza políticamente la posibilidad de generar alternativas, al relegar la dinámica socioeconómica a la regulación del mercado. La emergencia del pensamiento único funge como una pesada loza que restringe la reflexión teórica y la práctica política sobre el desarrollo. Este escenario se configura como una verdadera contrarrevolución. No obstante, ante la profundización de las asimetrías y desigualdades sociales y la evidencia de conflictos sociales de diverso signo, los promotores de la globalización neoliberal relanzan discursivamente la idea de desarrollo con una agenda acotada - pues no propone cambios estructu- 
rales e institucionales - que pretende, supuestamente, conferirle un "rostro humano" al neoliberalismo. En otro sentido, se registran distintos intentos por repensar el desarrollo desde una visión que pretende ser interdisciplinaria, y que en algunos casos reivindica la problemática de los países subdesarrollados. Se trata todavía de esfuerzos variopintos e incipientes, con una fuerte carga de eclecticismo (Parpart y Veltmeyer, 2004). Por la otra, aunque existe un cierto consenso nominal entre las teorías del desarrollo sobre los objetivos y valores (por ejemplo, bienestar social, elevación de niveles de vida, etcétera), se profundiza poco acerca de las causas del subdesarrollo, cómo afrontarlas y con qué recursos, quién encabeza y dirige el proceso y cuál es el sentido que se le quiere imprimir al desarrollo en un horizonte tentativo de cambio social. En otras palabras, aún es necesario trabajar con miras a la construcción de una visión integral, en términos estructurales y estratégicos, que contribuya a atacar las causas de fondo de las grandes asimetrías y desigualdades sociales que predominan en el capitalismo contemporáneo.

Los estudios sobre migración internacional han sido prolíficos en cuanto al uso de enfoques y teorías provenientes de distintos paradigmas y en aportar abundante evidencia empírica. Como se deduce al contrastar las visiones histórico-estructurales (acumulación primitiva, sobrepoblación, sistema-mundo) frente a perspectivas neoclásicas y sus derivados (push-pull, nueva economía, mercados laborales segmentados) o las visiones socioculturales (redes sociales, causación acumulativa y transnacionalismo). No obstante, también se verifica cómo, en el mayor de los casos, el vigor interpretativo decae cuando se renuncia a la construcción de teorías fuertes, o al utilizar teorías que sólo acometen una parte del fenómeno o que lo consideran aisladamente. Incluso se puede describir un itinerario de las teorías de la migración en atención a distintas fases del fenómeno —origen, desarrollo y consolidación - pero pocas veces se presentan esfuerzos explicativos que pretendan cubrir todo el amplio rango de la dinámica migratoria desde una perspectiva multidimensional. Y aunque existe un creciente intento por integrar los niveles micro, meso y macro, suele campear la perspectiva del norte, es decir, de los países receptores de migrantes, amén de que elénfasis en la temática del desarrollo es todavía marginal.

La mayor parte de los estudios que abordan directamente la relación entre migración y desarrollo giran en torno al primer factor, como si la migración fuese una variable independiente y las posibilidades o no de desarrollo estuviesen supeditadas a los recursos e iniciativas de los migrantes. Más aún, suelen centrarse en el ámbito local, comunitario o regional con un acentuado énfasis en el papel de las remesas y una visión limitada del desarrollo, lo cual desdeña la crucial dimensión macroestructural que modula el sistema migratorio y ofrece una visión reduccionista del transnacionalismo (Delgado Wise y Márquez, 2006). Con la pretensión de ilustrar de manera esquemática los linderos de esos enfoques analíticos, es posible diferenciar a grandes rasgos dos vertientes aparentemente contrastantes:

1. El círculovicioso. La migración y el desarrollo aparecen como conceptos antitéticos, especialmente cuando se hace referencia a la migración laboral en el horizonte sur-norte. Desde este ángulo, el fenómeno migratorio no tiene posibilidades de inducir dinámicas de desarrollo en los lugares de procedencia, sino que por el contrario provocan efectos adversos, tales como inflación, desarticulación productiva, abandono de actividades económicas y despoblamiento, mismas que a su vez promueven más migración. En estricto sentido, más que de un modelo teórico de migración y desarrollo, se trata de la construcción de diagnósticos que desde distintos miradores describen la tendencia que históricamente ha dominado esta relación en los países y regiones con alta incidencia migratoria. Al respecto, podrían mencionarse autores como Papadimetriou (1998) y Delgado Wise (2000), entre muchos otros. 
2. El círculo virtuoso. En el caso de procesos migratorios maduros, con redes sociales y organizaciones de migrantes consolidadas, se considera que existe la posibilidad de que la diáspora, en tanto agente, contribuya al desarrollo local y regional, así sea en términos restringidos. Esta perspectiva se sitúa en los pequeños márgenes que para un cierto desarrollo social permite la política neoliberal en el contexto de los países emisores. Este enfoque abarca una amplia gama de autores y perspectivas analíticas, incluso contrastantes, que ponen el acento en las remesas, en las organizaciones de migrantes o en ambas. Por su influencia política, en un primer plano se sitúan los organismos internacionales - como el BM (2006) y el BID (2000) - interesados en promover el neoliberalismo "con rostro humano", en consonancia con los postulados del Posconsenso de Washington. En segundo término se encuentran autores que han desarrollado una perspectiva más próxima a los intereses de la sociedad migrante, en una vertiente que puede ser calificada como "transnacionalismo desde abajo", la cual destaca el papel de las organizaciones de migrantes como sujetos potenciales de distintas modalidades de desarrollo regional y local (Moctezuma, 2005; García Zamora, 2005; Delgado Wise, Márquez y Rodríguez, 2004; Guarnizo y Smith, 1998).

Las dos vertientes analíticas tienen un punto en común: su horizonte analítico se restringe a la relación unidireccional migración-desarrollo, aunque difieren en que una niega las posibilidades de desarrollo, en tanto que la otra las pondera favorablemente. Indiscutiblemente, la segunda vertiente ha ganado más notoriedad, por lo que conviene hacer un recuento de los principales planteamientos académicos que han emanado de ella, a fin de sopesar sus alcances y limitaciones:

\section{1) Remesas e inversión productiva}

Durante las últimas dos décadas del siglo pasado, el fenómeno de la migración de trabajadores mexicanos a Estados Unidos se expande notablemente, teniendo como telón de fondo las políticas neoliberales y el proyecto de reestructuración productiva que estaba experimentando la economía de Estados Unidos. En lo concerniente a los estudios sobre migración y desarrollo (estudios centrados en el eje analítico remesas-inversión-desarrollo), se pueden establecer dos momentos sucesivos que han marcado lo esencial del debate, un debate que aún no encuentra una solución satisfactoria, ni en términos teóricos ni prácticos. A partir de los ochenta, Reichert (1981), Stuart y Kearney (1981), Mines (1981) y Wiest (1984) efectúan varios estudios empíricos en la región centro-occidente de México, donde se enclava Zacatecas, acerca de las remesas de dinero que los migrantes envían a sus lugares de origen. Estos autores argumentan que los efectos de las remesas en las comunidades de origen tienden a ser perniciosos: diferenciación social, inflación de los precios de la tierra, concentración de los recursos locales en pocas manos. Con posterioridad, los investigadores que les sucedieron habrían de identificar esos resultados como una visión pesimista ante la posibilidad del desarrollo regional impulsado con las remesas. Más adelante, en los noventa se analiza un círculo virtuoso entre remesas e inversión productiva (Durand, 1994; Jones, 1995; Durand, Massey y Parrado, 1996; Massey y Parrado, 1998), según lo cual las remesas se invierten en la agricultura y en capital humano, al tiempo en que el circulante monetario ejerce un efecto multiplicador benéfico para las economías de las comunidades, municipios y regiones. A sabiendas de que el uso de las remesas se canaliza mayormente a la subsistencia familiar, y en menor medida a la inversión productiva, algunos autores (Durand, 1994; Jones, 1995) sostienen que esas inversiones impactan significativamente en sectores y localidades específicos. Massey y Parrado (1998: 19) 
arguyen que la migración internacional es "fuente de capital productivo y fuerza dinámica que promueve la actividad empresarial, el establecimiento de negocios y la expansión económica”. Al ahorro generado por los migrantes se sumaría la consideración de las remesas colectivas (Goldring, 1996; Smith, 1998; Moctezuma, 2000) en tanto recurso para financiar inversiones productivas e infraestructura social, particularmente en aquellas zonas de alta migración donde la inversión pública y privada es raquítica. Con todo, el aspecto más interesante es la identificación de un nuevo sujeto social, el migrante colectivo (Moctezuma, 1999). Esta otra visión ha sido motejada como optimista, en oposición al pesimismo de los ochenta. Adicionalmente, el discurso institucional también ha sido catalogado como optimista, es el caso de la CEPAL (Torres, 2000), el Banco Mundial (Ratha, 2003) y el gobierno foxista (Lozano, 2005). Si bien existe un consenso respecto a que la mayor parte de las remesas se utiliza como gasto corriente de las familias (alimentación, vestido, vivienda, educación y salud, inclusive), no hay consenso respecto de las potencialidades de las remesas como fuente de inversión o capital. Además, se ventilan críticas al estudio de la migración y el desarrollo que tiene por eje las remesas (Binford, 2002; Canales y Montiel, 2004).

\section{2) Transnacionalismo y desarrollo}

En contraste con la suposición de que los migrantes al asentarse en la sociedad de destino rompen con su lugar de origen, el transnacionalismo subraya el proceso contrario: los inmigrantes, independientemente de su incorporación a la sociedad de destino, mantienen vigentes sus relaciones con su sociedad de origen. En defensa de ese argumento plausible se postula que: i) los migrantes mantienen vínculos con su país de origen para afrontar las condiciones de desigualdad racial y otras en el país de destino; ii) los procesos globales causan la migración y superan al Estado-nación, lo cual genera una sociedad civil global que amenaza el monopolio político del Estado, y iii) el transnacionalismo genera un "tercer espacio" para los inmigrantes entre el Estado y las sociedades de origen y destino. Al distinguir entre "transnacionalismo desde arriba" como ámbito de acción de las grandes corporaciones empresariales y financieras y los agentes políticos, y "transnacionalismo desde abajo", para referirse al ámbito del común de los migrantes, este enfoque abre la posibilidad de observar, en algún grado, la asociación entre procesos de desarrollo y migración. En el primer caso se trataría de la injerencia de las empresas transnacionales que harían negocio en el interior del proceso migratorio, como pueden ser las remesaras, la banca y en general empresas proveedoras de mercancías y servicios para los migrantes y sus familias. En el segundo caso se trataría del consumo que en los lugares de origen y destino realizarían los migrantes y sus familias. Al menos, la asociación entre transnacionalismo y desarrollo se ha explorado en dos vertientes: i) la economía de la migración, en la que prácticas transnacionales de los migrantes, como las llamadas telefónicas, el uso de tecnologías de la comunicación, el turismo, el comercio nostálgico y las remesas, desencadenan efectos positivos en las economías locales (Orozco, 2003), pero también abre nichos que a la postre son apropiados por las corporaciones transnacionales (Guarnizo, 2003), y ii) la contribución de las organizaciones de migrantes a procesos de desarrollo local y regional, particularmente en la realización de obras sociales de beneficio colectivo en los lugares de origen (Delgado Wise, Márquez y Rodríguez, 2004; Portes, Escobar y Walton, 2006).

\section{3) Codesarrollo}

La Unión Europea ha diseñado la política de codesarrollo fundada en la idea de la aportación de los migrantes al desarrollo de sus lugares de origen, aunada a la llamada cooperación para el desarrollo y, en los casos del este europeo, al fondo de cohesión europeo. El codesarrollo propone i) fomento de actividades productivas a través de las remesas; ii) formación y apoyo a los migrantes para que retornen; iii) involucrar a los migrantes en proyectos 
de cooperación; iv) la formación y orientación de emigrantes potenciales en los países de origen; v) el fomento y creación de puentes entre comunidades de origen, en el sur, y las que han emigrado al norte; vi) la implicación de los gobiernos nacionales, locales, organizaciones de la sociedad civil, empresariales, universidades, centros educativos y culturales e inmigrantes, y vii) la mejora de las condiciones de vida y trabajo de los emigrados. En los hechos, el codesarrollo se ha empleado como una política supraestatal para controlar el flujo inmigratorio, y no tanto para promover el desarrollo de los países donde se origina la migración. Los actores del codesarrollo, gobiernos, organizaciones de migrantes y ONG no comparten necesariamente una misma idea de ese concepto, pues suelen hacer sus propias interpretaciones en función de sus propios intereses. Además, el codesarrollo entraña una paradoja en el terreno de los hechos: mientras que al interior de la Unión Europea los países de menor desarrollo relativo, como España, fueron apoyados para activar su desarrollo nacional, con lo que pasaron de ser países exportadores de migrantes a importadores de inmigrantes (Agrela y Dietz, 2005), al exterior de la Unión Europea se recurre a la importación de fuerza de trabajo barata, pero se erige una suerte de fortaleza europea (Bendel, 2005) que cierra aparentemente las puertas a los inmigrantes y propone el codesarrollo, no tanto para promover el desarrollo de los países de origen como para encubrir una política de regulación de los flujos migratorios que provienen de los países que no forman parte de la Unión Europea.

\section{4) Sujetos sociales migrantes y desarrollo local} Para el caso de México, Moctezuma (2005) ha observado ciertas potencialidades asociadas a distintos tipos de migrante - colectivo, empresario, ahorrador y retirado- en materia de inversión social y productiva. Por su parte, García Zamora (2003) propone la constitución de una fundación para el desarrollo local y la adopción del sistema de microfinanciamiento. En tanto que Delgado y Rodríguez (2001) plantean que las organizaciones de migrantes pueden promover proyectos de desarrollo regional con el acompañamiento de políticas públicas. Desde nuestra perspectiva, la activación de alternativas de desarrollo en los ámbitos local y regional puede asumirse como un problema político que requiere la constitución de un sujeto social colectivo, portador de un proyecto que aglutine a los sectores migrantes y no migrantes, y que canalice la participación estatal en la promoción del desarrollo bajo con un esquema de planeación participativa.

Hoy en día se registra un auge de estudios circunscritos a la dirección migración-desarrollo. No obstante, dada la complejidad analítica que reviste esa relación, se advierte la necesidad de emprender estudios que se salgan de los linderos de ese esquema analítico, que tiene como punto de partida el fenómeno migratorio, para colocarse justamente del otro lado de la ecuación, es decir, de los macroprocesos de desarrollo. Este nuevo enfoque analítico considera la migración como un aspecto de la problemática del desarrollo y visualiza el desarrollo como un campo analítico cuyas dinámicas estructurales y prácticas estratégicas tienen como escenario los planos internacional, nacional y regional. Asimismo, ante el predominio de la visión teórica y política de los países desarrollados receptores de inmigrantes, es necesario trastocar esa hegemonía e incorporar la visión de los países subdesarrollados exportadores de migrantes. Y ante el predominio de perspectivas de corte nacionalista o localista, conviene impulsar el análisis comparativo de corte internacional que rescate la vasta experiencia global en materia tanto de desarrollo y de migración como de desarrollo y migración.

La perspectiva de la economía política del desarrollo tiene el cometido de explicar la dinámica migratoria a partir del análisis de la problemática del desarrollo. Analíticamente, la asociación entre reestructuración productiva y transnacionalización, diferenciación y precarización de los mercados laborales se aviene como el nudo crítico para explicar la problemática del desarrolloy los procesos migratorios internacionales en el capitalismo 
contemporáneo. No siempre es fácil apreciar ese nexo crítico, dado que el gran capital adquiere una faceta de ente abstracto cuando, mediante la internacionalización de la producción, bajo formas de reestructuración de la producción como la subcontratación y el trabajo a domicilio, despersonaliza y desterritorializa las relaciones sociales de producción. Pero al enfocarse a casos concretos, como la migración mexicana a Estados Unidos, con base en el influjo de la integración económica regional, sale a la luz el papel desempeñado por la fuerza de trabajo barata, en la que el migrante ocupa un lugar central, y el papel asignado a las remesas en el país de origen, como se analizará a continuación.

\section{El caso mexicano bajo la lupa de la economía política del desarrollo}

La forma como México se inscribe en la órbita del capitalismo estadounidense bajo el neoliberalismo y particularmente en el contexto del TLCAN, resulta fundamental para comprender el modelo de "desarrollo" adoptado en el país. Como ha sido documentado en otros trabajos, lo que impera en México, a contra sensu de lo que supondría el avance por la senda secundario-exportadora - por ejemplo, la instauración de un modelo exitoso de exportación manufacturera-, es en realidad un modelo de exportación de fuerza de trabajo barata (Delgado Wise y Márquez, 2005 y Delgado Wise Cypher, 2005). Este modelo, que resulta funcional al proceso de reestructuración productiva estadounidense, está integrado por tres mecanismos interrelacionados, que en su conjunto dan cuenta de una modalidad de integración asimétrica de la economía del país a la de Estados Unidos:

1. La industria maquiladora, conformada por plantas de ensamble asociadas a una estrategia de relocalización productiva comandada por grandes corporaciones de origen estadounidense para aprovechar bajos costos laborales en México. Para el país redunda en una muy baja integración a la economía nacionaly, en contrapartida, contribuye al desmantelamiento del aparto productivo.

2. La maquila encubierta, entendida como plantas manufactureras con procesos productivos más complejos que la maquila, pero cuya operación se rige con el mismo sistema de importación temporal que la maquiladora, como ocurre en los sectores automotor y electrónico. ${ }^{2}$

3. Lamigración laboral, que entraña el éxodo masivo de mexicanos a Estados Unidos, como resultado de la estrechez y precarización del mercado laboral mexicano y del proceso de integración neoliberal de la economía mexicana a la estadounidense.

Con base en estas grandes consideraciones, si a la exportación indirecta de fuerza de trabajo - maquila y maquila encubierta - se le suma la exportación directa de fuerza de trabajo — vía migración laboral- queda claro cuál es el contenido real de las exportaciones mexicanas: la fuerza de trabajo barata. De ahí la caracterización del modelo actual de crecimiento exportador como modelo exportador de fuerza de trabajo, más allá de la discusión de la dinámica del comercio exteriory de un presunto modelo deintegración bajo el paraguas de la convergencia económica.

El modelo exportador de fuerza de trabajo deja un saldo inexorable para la economía mexicana: desarticulación del aparato productivo, estancamiento económico, precarización del mercado laboral formal, expansión del sector informal, incremento de la pobreza, la marginación y las desigualdades sociales. Este escenario catastrófico, sumado al declive relativo de los mecanismos de exportación indirecta, provocan el incremento inusitado de la migración laboral a Estados Unidos en las últimas dos décadas: en esos años, 575 mil mexicanos abandonaron el país (CONAPO, 2006), en tanto que la población de origen mexicana radicada en Estados Unidos alcanzó la cifra de 28 millones y de 11 millones para la nacida en México; asimismo, en 2006 las remesas captadas por México alcanzaron los 23 mil millones de dólares, lo cual lo sitúa como el primer receptor mundial. 
Esta dinámica poblacional, reflejo del modo en que se inserta la economía mexicana a la de vecino país del norte, da cuenta de la formación de una gigantesca reserva laboral a disposición de la economía estadounidense, cuyos costos de formación recaen en la sociedad mexicana, amén de que la sangría laboral significa también pérdida de riqueza potencial para el país. Una parte significativa de esta fuerza de trabajo es indocumentada, debido a que de este modo la política inmigratoria estadounidense presiona a la baja el salario de los inmigrantes mexicanos y, de manera agregada, de la clase trabajadora ocupada en la economía estadounidense, en abono del proceso de reestructuración en curso.

Desde los setenta, el mercado laboral estadounidense está en proceso de reestructuración y precarización, en esa dinámica se inscribe el modelo exportador de fuerza de trabajo reseñado líneas arriba. Por lo que hace al papel específico de los migrantes, se puede argumentar que, a grandes rasgos, participan en dos segmentos laborales:

1. Un vasto sector de empleos cada vez más precarios en un escenario de ingente exclusión social que antecede a la reestructuración productiva (por ejemplo, agricultura, servicio doméstico y limpieza).

2. La emergencia de una significativa franja ocupacional precarizada asociada a la reestructuración productiva en diferentes ramas: sectores de punta, producción de bienes-salario eindustrias maduras en proceso de rescate.

En la distribución ocupacional de los inmigrantes, resalta la presencia creciente de éstos en la industria de la construcción, la manufacturera, los servicios y el comercio, sobre todo en segmentos degradados, también concebidos como el traspatio de la industria en reestructuración: sweatshops, subcontratación, trabajo domiciliario, day labor, etcétera.

Mientras que la reestructuración industrial ha afectado negativamente a los trabajadores de Estados
Unidos, los trabajadores mexicanos han experimentado sus consecuencias más agudas. El grueso de los inmigrantes mexicanos se ubica en un rango de poca calificación, bajos salarios, prestaciones limitadas o nulas, inestabilidad, con relaciones laborales unilaterales e informales - $\mathrm{O}$ autoritarias - riesgosas y sujetas a abusos extralegales de los empleadores (por ejemplo, salarios debajo del mínimo legal, despidos injustificados, escamoteo en el pago de horas extras).

La integración económica regional, articulada por el bloque de América del Norte y su instrumento el TLCAN, lejos de propiciar una convergencia económica, como postula la vertiente neoclásica, contribuye a profundizar las asimetrías entre los supuestos socios comerciales, México y Estados Unidos. En el período de aplicación del TLCAN, se han ensanchado un par de brechas por demás reveladoras: PIB per cápita y salarial. En lugar de que exista una convergencia vis-à-vis en el PIB per cápita, a la sazón indicador convencional del desarrollo, se registra un aumento de la brecha: mientras que en 1994 el PIB per cápita estadounidense representaba 2.6 veces más que el mexicano, en 2004 la relación se había ampliado a 2.9. Por su parte, el salario manufacturero estadounidense medido en dólares por hora hombre representaba 5.7 veces más que el mexicano en 1994 y 6.8 en 2004. Paradójicamente, mientras la zanja entre los ingresos salariales percibidos en México y Estados Unidos se abre cada vez más, no ocurre lo mismo con los niveles de productividad, los cuales han tendido a acortarse, incluso en ciertos casos la productividad es mayor en México en algunos sectores productivos, particularmente en aquellos que forman parte del modelo exportador de fuerza de trabajo mexicana.

\section{El advenimiento de la dependencia de las remesas}

La mayoría de los países exportadores de fuerza de trabajo no dispone de un proyecto de desarrollo nacional y, en contrapartida, se han sometido a las políticas de ajuste estructural impulsadas por el FMI y el BM 
y hacen descansar ciertas expectativas de desarrollo - particularmente en el plano local o regional - en la contribución de los migrantes a través de las remesas. Estos mismos recursos, a nivel macro, constituyen i) una fuente de ingreso externo que se abona a las cuentas nacionales y ii) un soporte de la estabilidad social, al mitigar la pobreza y la marginación y abrir una válvula de escape frente a las limitaciones de los mercados laborales locales, regionales y nacionales (RIMyD, 2005). Este modelo que está presente en países como México, El Salvador, Filipinas y Marruecos, en realidad constituye una perversión de la noción de desarrollo sin perspectiva de futuro.

Con relación al modelo de desarrollo basado en las remesas, los organismos internacionales — BM (2006); BID (2000), entre otros - han perfilado una agenda de políticas en materia de migración y desarrollo que pone en el centro el papel de las remesas en el desarrollo de los países de origen. Sin embargo, en la mayoría de los casos domina la perspectiva de los países de inmigración desde el rubro de seguridad, derechos humanos y gestión de la migración. El problema del desarrollo de los países emisores es visto básicamente como combate a la pobre$z a$. En este sentido, al anteponer seguridad y remesas sobre cooperación internacional, las políticas acometen sólo las manifestaciones y no las causas profundas de la migración. Los principios que dan cuenta del modelo de desarrollo basado en las remesas son cinco:

- Gestión de la migración. Desde una visión geoestratégica, se plantea lograr la gobernabilidad de los flujos migratorios, es una preocupación de los países desarrollados receptores de migrantes, desde una agenda de seguridad y la organización de bloques económicos regionales.

- Las remesas como instrumento del desarrollo. En ausencia de una política verdadera de desarrollo preferente de los países subdesarrollados, a la sazón los mayores emisores de emigrantes, se postula la idea de que los propios migrantes son generadores de recursos, por medio de las remesas, aptos para detonar el desarrollo de sus lugares de origen.

- La democratización financiera. El caudal de remesas registrado en el mundo configura un mercado atractivo para el lucro del capital financiero, al tiempo en que dota de servicios bancarios a los sectores excluidos. Los esquemas de ahorro y crédito con remesas se plantean como la palanca de procesos de desarrollo.

- El poder económico de los pobres. Las remesas pueden fungir como instrumento o motor del desarrollo, pues suponen que el impacto multiplicador de las remesas les confiere una suerte de poder económico a los pobres.

- La formación de capital humano. En presencia de un incontenible flujo migratorio, los países emisores podrían mejorar sus sistemas educativos y de formación técnica para que los migrantes laborales encuentren mejores opciones ocupacionales. A su vez, la posibilidad del retorno de los migrantes supone la posibilidad de ocupar mano de obra calificada en sus lugares de origen.

Por lo que hace al caso específico de México, se puede apreciar cómo el carácter subdesarrollado de la economía mexicana es resultado de su dependencia estructural ante la economía de Estados Unidos y, en un nivel más profundo, de la vulnerabilidad que representa confinar su desempeño económico a una ventaja comparativa estática y de corto plazo, como la exportación de fuerza de trabajo barato. Aunado a lo anterior, las evidencias arrojan un hecho por demás conspicuo acerca del errático desempeño de la economía mexicana: las remesas, en tanto expresión de la migración laboral, adquieren mayor relevancia en comparación a la maquila y la maquila encubierta. En ese sentido, el modelo exportador de fuerza de trabajo se decanta hacia su modalidad de exportación directa, misma que a su vez prohíja un modelo de desarrollo basado en las remesas. Este segundo modelo expresa, en realidad, el 
desarrollo de una dependencia crítica de las remesas tanto para la endeble estabilidad macroeconómica del país como para la frágil sustentabilidad social de importantes sectores poblacionales todavía radicados en México. Por tanto, el modelo de desarrollo basado en las remesas es un subproducto del proceso exportador de fuerza de trabajo vigente en la integración económica de México a Estados Unidos.

El sistema migratorio México-Estados Unidos configura un caso ilustrativo de la forma perversa en que la migración se convierte en una pieza fundamental de los procesos asimétricos de integración económica regional. En el concierto internacional, México se posiciona como el tercer receptor de remesas. En 2004, México captó 18.1 mil millones de dólares, después de India, con 21.7 mmdd, y China, 21.3 mmdd (Banco Mundial, 2006). A la par del crecimiento explosivo de la migración de mexicanos a Estados Unidos, las remesas han experimentado un crecimiento aún más espectacular para alcanzar en 2005 un monto de 20 mil millones de dólares (Banco de México, 2006).

Para la macroeconomía mexicana las remesas constituyen la segunda fuente de divisas, y hoy por hoy es la más dinámica y el soporte principal de la balanza comercial junto con el petróleo y la maquila, con la acotación de que el dinamismo del petróleo difícilmente puede mantenerse y la maquila se encuentra en franca fase de estancamiento desde 2000. Si bien México figura como el principal receptor de inversión extranjera directa - cuyo comportamiento es errático y no siempre productivo- de América Latina, su monto suele situarse por debajo de la captación de remesas.

En otro nivel, las remesas son una fuente de subsistencia familiar, y en esa medida configuran una suerte de paliativo ante fenómenos como la pobreza y la marginación social, pero paradójicamente constituyen un acicate para nuevas migraciones. Según estimaciones del Consejo Nacional de Población (CONAPO, 2005), hay 1.6 millones de hogares receptores de remesas familiares, de los cuales $47 \%$ tiene como principal fuente de ingreso ese recurso. La cantidad total de hogares receptores de remesas representa 8\% de los hogares del país, y si ese número de hogares se multiplica por cinco personas en cada hogar, resulta que 8 millones de personas reciben algún beneficio directo, lo cual representa 7.6\% de la población total del país en 2006 (104 millones de habitantes).

Diversos estudios sobre el uso de las remesas familiares en México coinciden en detectar un patrón de gasto similar en los hogares receptores de remesas. En efecto, su uso se canaliza principalmente a la satisfacción de necesidades básicas, incluidas salud y educación, y un remanente no mayor de $10 \%$ se destina al ahorro o a pequeñas inversiones en vivienda, terrenos, ganado y establecimientos comerciales. Además de estos usos, existen las llamadas remesas especiales destinadas a actividades de ahorro o inversión como la compra de una casa, maquinaria agrícola, participación en proyectos de inversión o en programas gubernamentales.

Existe un dato indirecto del impacto de las remesas como sistema paralelo de protección social de las familias mexicanas: el monto total asignado al Programa Oportunidades - principal programa del gobierno foxista para mitigar la pobreza extrema, que atiende a 5 millones de hogares y 25 millones de personas - representa apenas 15\% de las remesas familiares recibidas por México en 2005, mismas que fueron gastadas en educación y salud sin intermediación gubernamental (PNUD, 2006). De lo cual se desprende que en ausencia de las remesas familiares, el gobierno mexicano tendría que aumentar significativamente la inversión social para esos rubros.

Las remesas colectivas constituyen recursos recaudados por las organizaciones de migrantes destinadas a la realización de obras sociales y públicas en sus lugares de origen. Debido al entramado organizacional, al tejido de relaciones y a la necesaria negociación con los distintos niveles de gobierno (federal, estatal y municipal), las remesas colectivas configuran relaciones transnacionales acordes con la estirpe de las 
organizaciones de migrantes. Este tipo de remesas hace posible: i) la realización de obras en las localidades de origen que subsanan rezagos históricos en materia de infraestructura social; ii) el estrechamiento de vínculos socioculturales entre los migrantes y la población radicada en sus lugares de origen, y iii) el seguimiento y evaluación de las políticas públicas, lo cual eventualmente abre un canal institucional para la rendición de cuentas. El principal instrumento a través del cual se canalizan las remesas colectivas es el Programa Tres por Uno. En 2004, a través de este Programa se invirtieron 538.8 millones de pesos. Si se suman las cuatro fuentes de financiamiento (migrantes, municipio, estado y federación), dicha cantidad representa 3.24\% de lo que recibe el país por concepto de remesas familiares. No obstante, en localidades pertenecientes a entidades como Zacatecas y Jalisco su peso es significativo con relación a los montos de inversión pública en infraestructura y servicios.

El espectro de obras realizadas en este programa abarca desde la pavimentación de calles y rehabilitación de iglesias hasta obras de infraestructura productiva como carreteras y presas. Es pertinente acotar que los montos de inversión están sujetos a las restricciones presupuestales, principalmente, del gobierno federal, por lo cual muchos proyectos e iniciativas de las organizaciones de migrantes quedan fuera de la ejecución del programa.

Los proyectos sociales apoyados con remesas colectivas configuran una forma de transnacionalismo desde abajo que va más allá de la construcción de obras de infraestructura básica, puesto que entre otras cosas contribuye a: i) fomentar la organización transnacional de los migrantes; ii) posibilitar que las organizaciones de migrantes y sus comunidades de origen negocien con los tres niveles del gobierno mexicano; iii) financiar la construcción de miles de proyectos de infraestructura básica; iv) propiciar un proceso de aprendizaje social transnacional de todos los actores involucrados en esos proyectos, y v) fomentar la cultura de la transparencia y rendición de cuentas (García Zamora, 2005).
Pese a los aportes positivos de las remesas familiares y colectivas al bienestar de los hogares y las comunidades, por ningún motivo se puede plantear que sean el sustituto de las políticas públicas para el desarrollo económico, y tampoco para las políticas de desarrollo social.

Es común suponer que la pobreza produce migración, y que ésta a su vez produce remesas. Si las cosas fueran así, los estados y municipios con menores niveles de ingresos per cápita, tendrían un gran número de migrantes y, por lo tanto, recibirían un elevado monto de remesas. Sin embargo, la distribución geográfica de las remesas en México revela una realidad diferente. En términos absolutos, los estados de Michoacán, Jalisco, Guanajuato, México, Puebla, Veracruz, Guerrero, Oaxaca, Hidalgo y Distrito Federal concentraron 70\% de las remesas en 2004. Cada uno de ellos recibió remesas por más de 600 millones de pesos; Michoacán recibió 2,196 millones de dólares. En 2004, de esos 10 estados, seis de ellos (Michoacán, Puebla, Veracruz, Guerrero, Oaxaca e Hidalgo) pertenecen también al grupo de los 10 estados con menores niveles de desarrollo humano del país. Los otros cuatro receptores de remesas (Jalisco, Guanajuato, Estado de México y Distrito Federal) pertenecen al grupo de las 10 economías estatales más grandes del país. A pesar de su elevado nivel de desarrollo humano, estos estados concentran 32\% de las remesas recibidas en 2004. En comparación, cuatro de los 10 estados con bajo nivel de desarrollo humano (Chiapas, Zacatecas, Tabasco y Tlaxcala) suman solamente $7 \%$ de las remesas nacionales.

Al analizar la distribución geográfica de las remesas en términos relativos, la situación anterior se sostiene. Los 10 estados que reciben mayores remesas per cápita (Michoacán, Guanajuato, Zacatecas, Aguascalientes, Hidalgo, Guerrero, Nayarit, Oaxaca y Querétaro), con más de 215 dólares en 2004, se ubican en distintos niveles de desarrollo humano. Cinco de esos 10 estados (Michoacán, Zacatecas, Hidalgo, Guerrero y Oaxaca) se ubican entre los 10 estados con menor desarrollo 
humano. Todo esto revela que no existe una relación mecánica entre remesas y desarrollo humano a escala estatal, en la que es difícil diferenciar el impacto específico de las remesas.

Por otra parte, al enfocar la atención en el fenómeno de la pobreza referido específicamente a los hogares de México, un ejercicio de simulación realizado por Rodríguez (2005) muestra que sin el influjo de las remesas, el número de hogares ubicados en situación de pobreza crecería en poco más de 220 mil. Y aunque no existe un vínculo directo entre migración y pobreza, es evidente que las remesas familiares fungen como un paliativo para aminorar las condiciones de pobreza y marginación, sin que en ello medie la intervención gubernamental. Como lo muestran múltiples estudios sobre el impacto de las remesas familiares sobre la pobreza - entre otros, CONAPO $(1999,2000)$-, los hogares receptores de remesas tienden a presentar niveles de vida en términos de alimentación, salud, educación y vivienda ligeramente superiores a los hogares que no reciben remesas. Cabe destacar que 75\% de los hogares receptores de remesas en México no son pobres y que la mayor parte de las remesas se concentran en $492 \mathrm{mu}$ nicipios de alta intensidad migratoria y bajos niveles de pobreza. Además, debe considerarse que la emigración internacional implica un costo que se ha venido acrecentando con el reforzamiento de las medidas de control fronterizo; costo que los miembros de los hogares más pobres difícilmente pueden sufragar. Por ello no se deben establecer deducciones mecánicas sobre migración y pobreza. En el mejor de los casos, se puede señalar que la migración y las remesas son un atenuante de la pobreza y la marginación en las comunidades de origen. Pero no puede considerarse, de ninguna manera, que las remesas sean una solución de fondo para erradicar o combatir la pobreza.

En el ámbito económico, otra forma en que impacta la migración ocurre en la llamada industria de la migración, entendida como la cadena de actividades vinculadas directa e indirectamente a las migraciones internacionales en Estados Unidos y México. La migración, además de su impacto familiar, genera una serie de actividades asociadas que afectan las economías locales y regionales. A nivel macro varias empresas se benefician de la demanda de bienes y servicios que desencadenan las remesas: envío-recepción de remesas, telecomunicaciones, transportes, turismo y "mercado paisano". Dado el escaso desarrollo empresarial migrante, la industria de la migración es aprovechada mayormente por grandes empresas multinacionales, sobre todo de países receptores: Western Union, Money Gramm, AT\&T, City Bank, Continental, American Airlines, Wal-Mart, etcétera, y en menor medida de los emisores: Telmex, Mexicana, Cemex, etcétera. Además han emergido pequeñas y medianas empresas, como agencias de viaje y casas de cambio. En los lugares de origen, las remesas modifican los patrones de consumo hacia la compra preferente de mercancías estadounidenses, y en los lugares de destino se impulsa el mercado interno mediante el creciente poder de compra de los migrantes (en 2003 sus ingresos ascendieron a 272 mil millones de dólares), lo cual no deja de formar parte del engranaje que reproduce las asimetrías y mantiene el statu quo internacional (Guarnizo, 2003). En suma, se trata de una amplia gama de actividades económicas en los lugares de origen y destino inscritas en la lógica de la globalización neoliberal que, sin embargo, benefician, sobre todo, al país receptor, en este caso Estados Unidos.

México se inscribe en el modelo de remesas como desarrollo, al no disponer de una política integral y sustentable de migración y desarrollo. Los tres principales programas que supuestamente afrontan las causas de la migración -Contigo, TLCAN y Sociedad para la Prosperidad CONAPO (2004a) - apuntan en dirección opuesta al desarrollo y no atacan las causas del desbordamiento migratorio. En efecto, Contigo es una amalgama de programas asistenciales focalizados en la extrema pobreza; el TLCAN se ha consolidado como eje de la integración económica asimétrica de México a Estados Unidos, y Sociedad para la Prosperidad ha de- 
rivado en la Alianza para la Seguridad y la Prosperidad de América del Norte, esto es, una agenda geopolítica de seguridad acorde con los intereses de Estados Unidos.

Las políticas migratorias en México siguen una lógica adaptativa a través de programas inconexos y abocados a cubrir aspectos parciales relacionados con los efectos de la migración. La pretensión básica del gobierno es garantizar que la migración cumpla pasivamente su funcionalidad en el equilibrio macroeconómico y la estabilidad social. Los programas vigentes pueden ser agrupados en seis categorías:

i. Derechos humanos. Medidas de protección tendientes a cubrir algunos aspectos de los derechos humanos de los migrantes, es el caso de los Grupos Beta, el Programa Paisano, la matrícula consulary la misma ampliación de la red consular.

ii. Vinculación transnacional. El fortalecimiento de la identidad alrededor del concepto de comunidades mexicanas en el exterior, que da lugar a la formación del Instituto de los Mexicanos en el Exterior (IME), el cual cubre parcialmente varios ámbitos: vinculación, educación, salud.

iii. Derechos políticos. La promoción de los derechos ciudadanos en el ámbito binacional, a partir de la reforma de 1996 sobre la no pérdida de la nacionalidad mexicana y la aprobación del voto de los mexicanos en el exterior, en 2005, con una modalidad extremadamente acotada.

iv. Desarrollo social con remesas colectivas. El Programa Tres por Uno es un ejemplo de negociación que involucra un transnacionalismo "desde abajo" para la realización de obras de beneficio social y promueve, sin que sea un objetivo ex profeso, la organización binacional de los migrantes. Por su origen, este programa ilustra la confrontación de dos visiones "solidarias": una neoliberal (la del gobierno) y otra comunitaria (la de los migrantes).

v. Recepción de remesas. La reducción de los costos de transferencia y el uso financiero de las remesas, mediante la competencia y reciente tentativa de "bancarización", particularmente a través del Banco de Ahorro Nacional y Servicios Financieros y la Red de la Gente.

vi. Inversión de remesas. Uso productivo de las remesas que se cristaliza en un reducido catálogo de proyectos productivos individualistas y dispersos, los cuales difícilmente se inscriben en una perspectiva de desarrollo local o regional, es el caso del Programa Invierte en México, del Banco Interamericano de Desarrollo y Nacional Financiera.

\section{Contradicciones del modelo bajo el influjo de la integración económica regional}

Si bien el modelo exportador de fuerza de trabajo y su derivado, el modelo de desarrollo basado en las remesas, resultan complementarios y funcionales para la expansión de la economía estadounidense y para la estabilidad socioeconómica mexicana, hay también signos que dan cuenta de su insustentabilidad. La migración México-Estados Unidos no puede verse como una fuente inagotable de fuerza de trabajo barata en la medida en que comienza a perfilarse una creciente tendencia al despoblamiento que abarca ya a 34\% de los municipios mexicanos (INEGI, 2006). A esto se aúna el dilema que entraña la explotación laboral extrema y el crecimiento de la pobreza y marginación social, que son caldo de cultivo de potenciales conflictos sociales y de seguridad, justo cuando los organismos internacionales encabezados por la ONU hacen un llamado para alcanzar los Objetivos de Desarrollo del Mileno. El escenario de pobreza y marginación se cierne en estados con alta incidencia migratoria, como Zacatecas, Michoacán, Oaxaca, Guanajuato y Jalisco, cuya afluencia de remesas no se traduce en desarrollo.

En un plano más general, las implicaciones del modelo exportador de fuerza de trabajo para la economía y sociedad mexicanas, se pueden resumir en cuatro grandes rubros: 
i. Eldesencadenamiento de procesos de desacumulaciónen la economía mexicana. Las exportaciones de la maquila y la maquila encubierta implican la transferencia neta de ganancias a la economía de Estados Unidos, ello da cuenta de una nueva modalidad de dependencia, más severa que las vislumbradas por la teoría estructuralista de CEPAL y la teoría de la dependencia.

ii. La transferencia de los costos de producción de la fuerza de trabajo exportada. La migración laboral significa para México una creciente sangría de recursos humanos que trae consigo el abandono de actividades productivas, la dilapidación de los costos de formación y reproducción de esa fuerza laboral y, en cierto sentido, el desplazamiento de mano de obra calificada en términos relativos.

iii. El desmantelamiento de buena parte del aparato productivo en México. A través de los costos colaterales derivados de las políticas institucionales orientadas a favorecer y mantener el modelo exportador, se ha producido un creciente desmantelamiento de la producción orientada al mercado interno. Al menos 40 cadenas productivas del sector de pequeñas y medianas empresas mexicanas han sido destruidas a raíz de la reorientación de la economía al mercado externo (Cadena, 2005).

iv. La dependencia crítica de las remesas en la estabilidad socioeconómica de México. Para la macroeconomía mexicana, las remesas constituyen la fuente más dinámica de divisas y el soporte principal de la balanza comercial, junto con el petróleo y la maquila, aunque el dinamismo petrolero difícilmente puede mantenerse y la maquila se encuentra estancada. Por otra parte, las remesas representan una fuente de subsistencia familiar. CONAPO (2004b) estima que hay 1.6 millones de hogares receptores de remesas ( $8 \%$ de los hogares del país), para $47 \%$ de los cuales es su principal fuente de ingreso. Las remesas familiares se canalizan sobre todo a la satisfacción de necesidades básicas, incluidas salud y educación, y un remanente no mayor del 10\% al ahorro o a pequeñas inversiones en vivienda, terrenos, ganado y establecimientos comerciales. Una de las funciones principales de las remesas familiares ha sido fungir como paliativo frente al problema de la pobreza (Rodríguez, 2005), sin que por ello se puedan considerar como sustitutas de las políticas públicas para el desarrollo socioeconómico.

A manera de síntesis cabe advertir tres puntos críticos sobre el papel de las remesas en la economía mexicana:

i. En virtud de la dependencia crítica de las remesas como fuente de divisas, es necesario tomar conciencia de que las remesas tenderán a caer debido a la migración definitiva, la reunificación familiar y la creciente tendencia al despoblamiento. Por tanto, ese recurso no puede considerarse como una fuente sustentable para el mantenimiento de la estabilidad macroeconómica de México ni mucho menos como un motor del desarrollo regional o regional.

ii. El patrón de uso de las remesas está volcado hacia el consumo familiar y en mucho menor medida a la inversión productiva. Por tanto, es inconsistente suponer que las remesas pueden constituir un fondo social de inversión que detone el desarrollo local o regional. En ausencia de un sistema financiero mexicano que derrame recursos crediticios a las localidades y regiones de origen de los migrantes, el esquema de microfinanzas asociado a la captación de remesas es todavía muy endeble como para visualizarlo como alternativa de desarrollo (Cortina y De la Garza, 2005).

iii. Las remesas no constituyen un recurso suficientes para elevar el ingreso de la población y para contrarrestar los niveles de pobreza, es decir, no pueden suplir las responsabilidades gubernamentales en materia de combate a la pobreza y promoción del desarrollo social. 


\section{Notas}

${ }^{1}$ Previamente, el ingreso de los migrantes ha sido considerado como una indispensable fuente de divisas que contribuye a subsanar las cuentas macroeconómicas y aliviar estragos sociales lacerantes como la pobreza.

${ }^{2}$ Es pertinente subrayar que la maquila y la maquila encubierta comparten dos características: i) carecen prácticamente de encadenamientos productivos hacia delante y hacia atrás con el resto del aparato productivo nacional, y ii) están sometidas a fuertes procesos de precarización laboral con salarios que oscilan, frente a los salarios manufactureros en Estados Unidos, en una relación de 1/10 en la maquila y l/7 en la maquila encubierta. Debido al elevado componente importado que involucran (entre $80 \%$ y $90 \%$ de las exportaciones totales), su contribución a la economía mexicana se reduce básicamente a la derrama salarial, esto es, al valor de la fuerza de trabajo incorporado a las exportaciones. Esto significa que se trata de una exportación indirecta de fuerza de trabajo o, si se quiere, de exportación de fuerza de trabajo sin que los trabajadores mexicanos salgan del país (Tello, 1996). Este es un elemento conceptual crucial que desmitifica el carácter supuestamente manufacturero de las exportaciones mexicanas, y que da cuenta de una regresión en la plataforma exportadora.

\section{Bibliografía}

Agrela, B. y Dietz, G., 2005, "Emergencia de regímenes multinivel y diversificación público-privada de la política de inmigración en España", Migración y Desarrollo, no. 4.

Banco de México, 2006, Informe anual 2005, Banxico, México. Banco Mundial, 2006, Global Economic Prospects. Economic Implications of Remittances and Migration 2006, Banco Mundial, Washington.

Bendel, P., 2005, “iBlindando la 'fortaleza europea’? Intereses, valores y cambios jurídicos en la política migratoria de la Unión Europea", Migracióny desarrollo, no. 4.
BID, 2000, "Capitalización de remesas para desarrollo económico local", Memorando de donantes.

Binford, L., 2002, Remesas y subdesarrollo en México, Relaciones, vol. XXIII, no. 90.

Cadena, G., 2005, Manufactura, en la ruta de la 'desindustrialización', El Financiero (16 de agosto).

Canales, A. y Montiel, I., 2004, "Remesas e inversión productiva en comunidades de alta migración a Estados Unidos, El caso de Teocaltiche, Jalisco", Migraciones internacionales, vol. 2, no. 3.

CONAPO, 1999, La situación demográfica de México, CONAPO, México.

CONAPO, 2000, Migración México-Estados Unidos. Presente y futuro, CONAPO, México.

CONAPO, 2004a, Informe de ejecución del Programa de Acción de la Conferencia Internacional sobre la Población y el Desarrollo, CONAPO, México.

CONAPO, 2004b, La nueva era de las migraciones. Características de la migración internacional en México, México, CONAPO.

CONAPO, 2005, Migración internacional, http://www. CONAPO.gob.mx.

CONAPO, 2006, "El CONAPO, el INEGI y el Colmex concilian cifras sobre la dinámica demográfica del país para el período 2000-2005", comunicado de prensa 37/06, en http;/www.CONAPO.gob.mx/ prensa/2006/372006bol.pdf, consultado el 19 de septiembre de 2006.

Cortina, J. y de la Garza, R., 2005, "Remesas: límites al optimismo", Foreign Affairs en Español, vol. 5, no. 3.

Delgado Wise, R., 2000, "Consideraciones sobre la estructura económica y social de Zacatecas de cara al siglo XXI", en R. García Zamora y J.M. Padilla (coords.), Los retos demográficos de Zacatecas en el siglo XXI, UAZ, México.UAZ.

Delgado Wise, R. y Cypher, J., 2005, The Strategic role of Labor in Mexico's Subordinated Integration into the US Production System Under NAFTA. Documento de trabajo 12/11/2005, Doctorado en Estudios del Desarrollo-UAZ. 
Delgado Wise, R. y Márquez, H., 2005, “Migración, políticas públicas y desarrollo. Reflexiones en torno al caso de México", ponencia presentada en el Seminario Problemas y Desafíos de la Migración y el Desarrollo en América, Red Internacional de Migración y Desarrollo, 7-9 de abril, Cuernavaca.

Delgado Wise, R. y Márquez, H., 2006, "The MexicoUnites Status Migratory System: Dilemmas of Regional Integration, Development, and Emigration", ponencia presentada en la Conferencia Migration and Development: Perspectives from the South, 10-13 de julio, Bellagio, Italia.

Delgado Wise, R. Márquez, H. y Rodríguez, H., 2004, "Organizaciones transnacionales de migrantes y desarrollo regional en Zacatecas", Migraciones internacionales, vol. 2 no. 4, Colef, Tijuana.

Delgado Wise, R., y Rodríguez H., 2001, "The emergente of collective migrants and their role in Mexico's local and regional development", Canadian journal of development studies, vol. XXII, no. 3.

Durand, J., 1994, Más allá de la línea: patrones migratorios entre México y Estados Unidos, CNCA, México.

Durand, J., Parrado, E. y Massey, D., 1998, ¿Nuevas regiones migratorias?, en R. Centeno (coord.), Población, desarrollo y globalización, Sociedad Mexicana de Demografía/ El Colegio de la Frontera Norte, México.

García Zamora, R., 2003, Migración, remesasy desarrollo local, Doctorado en Estudios del Desarrollo UAZ, México,

García Zamora, R., 2005, Migración, remesas y desarrollo. Los retos de las organizaciones migrantes mexicanas en Estados Unidos, Doctorado en Estudios del Desarrollo, México.

Goldring, L., 1996, "Blurring Borders: Constructing Transnacional Community in the Process of Mexico-U.S. Migration", Researchin Community Sociology, vol. 1.

Guarnizo, L. y Smith, M. (eds.), 1998, Transnationalism From Below: Comparative Urban And Community Research, New Brunswick: Transaction Publishers.

Guarnizo, L., 2003, "The economics of transnational life", International Migration Review, vol. 37, no. 3.

INEGI, 2006, II Conteo de Poblacióny Vivienda, Aguascalientes.
Jones, R., 1995, Ambivalent Journey: U.S., Migration and Economic Mobility in North-Central Mexico, University of Arizona Press, Tucson.

Lozano, F., 2005, "De excluidos sociales a héroes sexenales, Discurso oficial y remesas en México", en R. Delgado Wise y B. Knerr (coords.), Contribuciones al análisis de la migración internacional y el desarrollo regional en México, Miguel Ángel Porrúa/ UAZ, México.

Massey, D. y E. Parrado, 1998, "International Migration and Bussines Formation in Mexico", Social Science Quarterly, vol. 1, no. 79.

Mines, R., 1981, "Developing a Community Tradition of Migration to the United States. A Field Study in Rural Zacatecas, Mexico, and California Settlement Areas", Monographs in U.S.,Mexican Studies, no. 3.

Moctezuma, M., 1999, Redes sociales, comunidades filiales, familias y clubes de migrantes, El circuito migrante Sain Alto, Zac.-Oakland, Ca., Tesis de doctorado, El Colegio de la Frontera Norte, Tijuana.

Moctezuma, M., 2000, "La organización de los migrantes zacatecanos en Estados Unidos”, Cuadernos Agrarios, no. 19-20.

Moctezuma, M., 2005, "Morfología y desarrollo de las asociaciones de migrantes mexicanos en Estados Unidos. Un sujeto social y político extraterritorial", Migración y desarrollo, no. 5

Orozco, M., 2003, Worker Remittances in an International Scope, Washington, Inter-American Dialogue.

Papadimetriou, D., 1998, "Reflections on the Relationship between Migration and Development", Seminar on International Migration and Development in North and Central America, México, 2l-22 de mayo.

Parpart, J. y Veltmeyer, H., 2004, “The Development Project in Theory: A Review of its Shifting Dynamics", Canadian Journal of Development, Special Issue.

PNUD, 2006, Taller sobre el informe de bienestar humano en México, 7 de febrero, México.

Portes, A., Escobar, C. y Walton, A., 2006, "Organizaciones transnacionales de inmigrantes y desarrollo. Un estudio comparativo", Migración y desarrollo, no. 6. 
Ratha, Dilip, 2003, “Workers' Remittances: An Important and Stable Source of External Development Finance", en World Bank, Global Development Finance 2003: Striving for Stability in Development Finance, Banco Mundial, Washington.

Reichert, J., 1981, "The Migration Syndrome: Seasonal U.S. Wage Labor and Rural Development in Central Mexico", Human Organization, vol. 1, no. 40.

RIMyD (Red Internacional de Migración y Desarrollo), 2005, "Declaración de Cuernavaca", Migración y desarrollo, no. 4.

Rodríguez, H., 2005, "Tendencias recientes de la migración de mexicanos a Estados Unidos", Segunda Conferencia Internacional sobre la relación Estado-Diáspora.

Smith, R., 1998, "Transnational localities: Community Technology and the Politics of Membership within the Context of Mexico and U.S. Migration", Comparative Urban and Community Research, no. 6.
Stuart, J. y M. Kearney, 1981, "Causes and Effects of Agricultural Labor Migration from the Mixteca of Oaxaca to California", Working Paper in U.S.-Mexican Studies, no. 28.

Tello, C., 1996, "La economía mexicana: hacia el tercer milenio", Nexos, no. 223.

Torres, F., 2000, "Uso productivo de las remesas en México, Centroamérica y República Dominicana. Experiencias recientes", en Simposio sobre Migración Internacional en las Américas, Organización Internacional para las Migraciones/Comisión Económica para América Latina y el Caribe, San José de Costa Rica, 4-6 de septiembre.

Wiest, R., 1984, "External Dependency and the Perpetuation of Temporary Migration to the United States", en R. Jones (ed.), Patterns of Undocumented Migration: Mexico and the United States, Rowman \& Allanheld, Totowa. 